\title{
Radical cystectomy for bladder cancer: A qualitative study of patient experiences and implications for practice
}

by Margaret I. Fitch, Debbie Miller, Sharon Sharir and Alison McAndrew

\begin{abstract}
Patients being treated for bladder cancer share issues in common with other cancer patients, but also experience issues that are unique to their surgical treatment. This study used a descriptive qualitative approach to explore the experiences of patients who had undergone radical cystectomy for bladder cancer. Twenty-two participants were interviewed in-depth on one occasion and were invited to attend a focus group session following the analysis of the interview transcripts. Participants described the shock of their diagnosis, their lack of information about bladder cancer, the importance of clear communication with care providers, and the types of adjustments they had to make following surgery. Specifically, changes in bodily function, body image, sexual relationships, and intimacy presented challenges for these participants. Although there was a sense of acceptance about the treatment-related events, there were still significant adjustments required by individuals following their surgery. Information, open communication, and support from family and friends were seen as important factors in helping patients adjust after surgery. Patients require clear, concise and consistent information about their cancer, treatment options, and course of care. Nurses caring for patients following surgery for bladder cancer need to understand the unique needs of these patients.
\end{abstract}

\section{Background}

Bladder cancer is the sixth most common malignancy among Canadians (Canadian Cancer Society, 2009). The incidence in men is about three times that of women, but women with bladder cancer have a $30 \%$ to $50 \%$ greater chance of dying from their disease compared to men (Madeb \& Messing, 2004).

Radical cystectomy is the primary treatment modality for individuals with muscle invasive, organ-confined disease (Stage T2) with or without the addition of neoadjuvant/adjuvant chemotherapy for higher stage bladder cancer (Stage T3-4) (Patel \& Campbell, 2009). Due to anatomical differences in the pelvis, this surgery is performed differently in men and women. In men, the bladder and prostate are removed; in women, the uterus, ovaries, fallopian tubes, urethra and anterior vaginal wall are resected in addition to the bladder and pelvic lymph nodes (Patel \& Campbell, 2009). Urinary tract reconstruction options for this patient population include ileal conduit (stoma with external appliance), neobladder (internal pouch with voiding or

\section{About the authors \\ Margaret I. Fitch, $R N$, PhD, Odette Cancer Centre, 2075 Bayview Ave., Toronto, ON M4N 3M5. Tel: 416-480-5891; Fax: 416-480-7806; Email: marg.fitch@sunnybrook.ca}

Debbie Miller, RN, BSCN, MN, CETN (C), Odette Cancer Centre, Sunnybrook Health Sciences Centre, Toronto, ON.

Sharon Sharir, MD, MPH, FRCSC, Odette Cancer Centre, Sunnybrook Health Sciences Centre, Toronto, ON (at the time of the study).

Alison McAndrew, BA, RAP, Odette Cancer Centre, Sunnybrook Health Sciences Centre, Toronto, ON. catheterizing per urethra), or continent reservoir (internal pouch with catheterization per abdominal wall stoma). Due to the intimate nature of this procedure, radical cystectomy can have a significant impact on sexuality (Hart et al., 1999; Nordström \& Nyman, 1992; Zippe et al., 2004). Psychosexual issues can, in turn, affect patients' overall quality of life (Tabano, Condosta, \& Coons, 2002; Lagana et al., 2005).

The current literature reveals a relative lack of information about the experiences of this population, particularly for women. Systematic reviews of studies comparing quality of life in radical cystectomy patients with different types of reconstructive procedures, using any type of measurement instrument between 1966 to 2008, have failed to show that one type of urinary diversion is significantly better than another based on quality of life outcomes (Gerharz et al., 2005; Porter \& Penson, 2005; Somani, Gimlin, Fayers, \& N'dow, 2009). Virtually all studies reported used traditional clinical interview, chart review, and questionnaire methodology to assess patient experiences (Dutta et al., 2002; Hart et al., 1999; Henningsohn, Steven, Kallestrup, \& Steineck, 2002; McGuire, Grimaldi, Grotas, \& Russo, 2000; Nordström \& Nyman, 1992). One study utilized a qualitative approach to explore patients' lived experiences (Beitz \& Zuzelo, 2003). However, this study only examined patients who had a neobladder constructed and made few comparisons between the experiences of women and men.

Even among the studies that have been published, little attention has been focused on the potentially unique experiences of women undergoing this type of surgery. This may be because more men than women undergo this type of surgery, a male-oriented culture exists among urologists (Schover, 2004), or the difficulty in assessing sexual dysfunction in men and women in a comparable fashion (Nordström \& Nyman, 1992; Porter \& Pendson, 2005). The experiences of women and men may be very different for a number of reasons, including anatomic differences (Porter \& Pendson, 2005) and, possibly, differences between male and female perspectives. There is some suggestion that women have lower sexual desire and a more negative body image following radical cystectomy than do men (Hart et al., 1999). Meanwhile, Henningsohn et al. (2002) report women following radical cystectomy were more similar to a matched control population than were men when matched appropriately. A qualitative study of Beitz and Zuzelo (2003) reported some differences in the experiences of women and men. Women expressed more concern about surgical scars while men had difficulties finding clean, appropriate areas for sitting to void or catheterizing when using public bathrooms. Because there has been minimal work done in this area, it is unclear if women's pre- and post-operative needs differ from those of men when experiencing treatment for bladder cancer.

\section{Purpose}

The aim of this study was to gain a better understanding of the experiences of individuals who had undergone radical cystectomy for bladder cancer. We wanted to explore their perspectives about quality of life after surgery, with a focus on intimacy, sexuality, body image, and sense of femininity/masculinity. We engaged in an indepth interview with individuals who had undergone the procedure during the previous 12 to 36 months. This time period was chosen because it represents a point when patients' postoperative situation has stabilized, but is still close to the time of surgery (Kulaksizoglu, Toktas, Kulaksizoglu, Aglamis \& Unlüer, 2002). The study provided an open-ended exploration of patients' experiences, specifically eliciting information regarding sexuality and self-concept. 
This study is important because there has been limited work examining patient's quality of life and sexuality following radical cystectomy, little information on gender similarities and differences in this regard, and no qualitative studies that have included patients with all types of urinary diversions. By gaining a deeper understanding of the experiences of patients undergoing radical cystectomy, it would inform us about areas where improvements could be made.

\section{Methods}

Design

The study used a descriptive qualitative approach (Giorgi, 1985; Thorne et al., 1997) to explore the experiences of patients who had undergone radical cystectomy for bladder cancer. Each participant was interviewed on one occasion 12 to 36 months after his or her surgery. This time period allowed for patients to have experienced and coped with the changes following surgery.

\section{Sample and procedures}

Prior to undertaking the study, the protocol was approved by the hospital research ethics committee. Eighty potential candidates (40 men and 40 women) who had undergone radical cystectomy in the previous 12 to 36 months were identified from a list of all bladder cancer patients in the hospital database. The Bladder Cancer Information System (BLIS) has ethics approval from the Sunnybrook Research Ethics Board for use as a research database. Additional eligibility criteria for our study included 18 years of age or older, good command of English, and no known psychiatric history.

Potential study candidates were contacted initially through a standard letter signed by their surgeon that explained the purpose of the study, the nature of study involvement, and the plan for further contact by the research team. The research assistant subsequently contacted patients by telephone and explained the study in greater detail, answered patients' questions, and determined patient willingness to be involved in the study. For those patients who agreed to participate, a written consent was obtained at the time of the interview. Accrual was stopped when we observed no new perspectives were emerging from the interviews.

Demographic and clinical data were gathered through review of the bladder cancer information database, while the information about the patients' experiences was gathered through interview. Each person was interviewed on one occasion for approximately 60 minutes, using the interview guide (see Appendix A). The interviewer was a skilled qualitative interviewer with a background in psychology and psychosocial research. The interviews occurred in a private, comfortable room at the cancer centre or in the patient's home. The entire session was audiotaped and transcribed verbatim for future analysis.

Following the analysis of the interview transcripts, participants were invited to attend a focus group session in which the preliminary analysis results were presented. The focus group session provided an opportunity for additional input by the participants and reaction to the analysis. Because of the intimate nature of the material being explored, focus groups were held separately for women and men, in an effort to make participants as comfortable as possible.

\section{Interview/focus group guides}

The interview schedule (Appendix A) was designed specifically for this study. The questions are open-ended and developed to explore the participant's experiences and perceptions about: 1) being diagnosed with cancer, 2) undergoing surgery for the cancer, and 3) living with the changes following surgery. The schedule was used by the interviewer to ensure that all aspects were discussed. However, initially the participant was allowed to talk about topics that were important to her/him. Probes were only used if specific topics (e.g., quality of life, sexuality, body image, and sense of femininity/masculinity) were not discussed by the person in the initial part of the conversation. Although we anticipated the interview would take about an hour to complete, we allowed the participants to share as much as they wished to share.
The question guide for the focus group was developed for the purposes of this work, as well. Initially, the study results were shared with the participants using a PowerPoint presentation. The participants were then asked to comment on the results in terms of 1) the relevance to their own experience, 2) what they found surprising, if anything, and 3) the clarity of the description about the results. The participants were also invited to add any additional comments they wished to make about the results and the recommendations that ought to be made for future action. The latter invitation was couched specifically around the topics of education for future patients and advice to health care professionals caring for patients undergoing surgery for bladder cancer. Both written notes and an audiotape were made during the session.

\section{Data analysis}

The analysis of the interview transcripts followed a process of content and theme identification (Giorgi, 1985; Thorne et al., Sandelowski, 1997). The audiotapes were transcribed verbatim and the transcripts entered using IN-VIVO software for qualitative analysis. The members of the research team reviewed the entire set of transcripts separately, making marginal notes about potential codes for content categorization. The members then met and discussed their ideas about meaningful content codes and agreed upon the categories to organize the content. This categorization scheme was then used to code the entire set of transcripts. Examples of the categories included "communication", "information seeking", and "sexual relationships".

Using the coded information for each content category, each team member then reviewed these data separately and identified key ideas or common perspectives within each category. The team then met to discuss their perspectives and come to agreement about the fundamental notions contained in the material. These notions or key ideas were seen as capturing the main themes regarding the experiences of individuals undergoing surgery for bladder cancer.

The analysis was subsequently presented to the focus group attendees. The notes from the focus group meeting and the audiotape were subjected to a review by two members of the team. They determined if there were substantial changes required in the preliminary description of the results and whether any new information needed to be added.

\section{Rigour and credibility of the study itself}

Ensuring rigour in qualitative inquiry means that steps are taken to be certain the findings are representative of the experience of the participants and that there is a sense of trustworthiness about the data and its analysis (Connelly \& Yoder, 2000). Rigour is measured using the criteria truth value (creditability), applicability (fittingness), consistency (auditability), neutrality (freedom from bias), and confirmability (Lincoln \& Guba, 1985; Sandelowski, 1986; Sandelowski, 1993). In this study, clarification of the investigators' intentions, and tracking the analytic process and decision-making were completed through the following steps: (1) consent forms and study documents clearly described the intentions and purposes of the study, (2) researcher team members wrote their perspectives about the topic area prior to engaging in data collection or analysis, (3) careful notes were maintained throughout the study to document the decision trail and conceptualizations that emerge during data collection and analysis, (4) peer (researcher team members) debriefing allowed for discussion of the development of categorization codes and themes, and (5) alternative explanations for results were sought through member checking in focus groups and review of the literature. Establishing "truth value" occurred by (1) intentionally drawing out the perspectives of the participants, (2) member checking in the focus group to validate the researcher descriptions and interpretation of the results, and (3) presentation of the findings to other members of the cancer care team, prior to writing this article, to determine the fit with other contexts outside the study setting. 


\section{Results}

\section{Selected demographics of sample}

Twenty-two individuals (13 men and nine women) who had undergone radical cystectomy for bladder cancer from two institutions participated in this study (see Table 1). Twelve of the participants were married. Twelve had a neobladder (NB) and 10 had an ileal conduit (IC). There were no participants with a continent reservoir.

\section{Content and themes}

The participants provided very rich and full descriptions about their experiences prior to and following their radical surgery for bladder cancer. For the purposes of this article, overall results will be summarized with illustrative quotations from participants. In-depth descriptions about certain aspects of the work (i.e., gender differences, body image, sexuality) will be written for subsequent articles.

Lack of knowledge about bladder cancer. Overall, participants expressed a lack of understanding about bladder cancer, its causes and associated risk factors. They believed this often led to a delay in their cancer diagnosis. They all had experienced symptoms of bladder cancer, but had not realized the symptoms could be signs of cancer. Had they realized the serious nature of the symptoms, they likely would have sought a physician out sooner than they did.

Being female, [bleeding] doesn't really panic you for some unearthly reason... and my bleeding stopped, so I ignored it and I figured, oh well...there's no pain with this. (F 74, NB)

So I'm driving home and I'm saying, "Okay, you've got cancer, that's interesting and you should stop smoking." I don't know what smoking has to do with the bladder. (F $75 \mathrm{NB}$ )

Feeling shock and fear at diagnosis. All participants were surprised at being diagnosed with bladder cancer. Initially, some felt a loss of control while others were more accepting of the diagnosis. Most described a sense that death felt like a close reality for them now.

I was stunned when I realized that's what it was. Because there is no history of cancer in the family or anything like that...it was very surprising to me. $(F, 74, N B)$

... it was very hard, I was scared... I was very fatalistic. I figure whatever's going to be. I mean, I have no control and I'm in the hands of the doctors and whatever they want me to do, I will do. (F $64 \mathrm{NB}$ )

... the general public feels that cancer is almost a death sentence, you know. You're sitting there thinking, I'm going to die. (F 73 IC)

Table 1. Patient Demographics

\begin{tabular}{|l|l|l|}
\hline Demographics & Men $(\mathbf{N}=\mathbf{1 3})$ & Women $(\mathbf{N}=\mathbf{9})$ \\
\hline Sunnybrook Patients & 11 & 3 \\
\hline University Health Network Patients & 2 & 6 \\
\hline Average Age & 68.4 & 73.1 \\
\hline Age Range & $44-82$ & $58-85$ \\
\hline Married/Common Law & 10 & 2 \\
\hline Widow/Widower & 0 & 3 \\
\hline Divorced & 2 & 3 \\
\hline Single & 1 & 1 \\
\hline Ileal Conduit & 5 & 4 \\
\hline Neobladder & 9 & 4 \\
\hline $\begin{array}{l}\text { Neobladder converted to } \\
\text { Ileal Conduit }\end{array}$ & 0 & 1 \\
\hline
\end{tabular}

Desire for open communication. Open communication with health care professionals was seen by all participants as critical. Many said this was extremely important in their interactions with care providers. They wanted information about bladder cancer and about treatment plans to be clear, consistent from professional to professional, and provided in a timely fashion to avoid anxiety and confusion. For most, this had not been the way they received information.

Well, I'm thinking he said tumour, and it was malignant tumour, but doesn't that mean cancer?...he did not really say cancer. I wasn't too happy with the treatment I was getting. Because all three doctors would come at different times to see me and each would have something different to say. (F74 NB)

Oh, the detail, anything I asked for or wanted to know about [I could ask]...I couldn't believe it, it was absolutely incredible the level of information [but it was overwhelming]. (M 68 IC)

Desire for information. The need to search for additional information or speak with others who had bladder cancer or urinary diversions was important for most participants, but was an activity that was frequently left up to them. They believed it was helpful if family and friends were present when they received information from health care providers. Often "connections" with others or "word of mouth" were used to find urologists or additional information.

... it was nice my wife was there [at the doctor's appointment] 'cause we could compare notes later... it's the only way to receive the information really. I suppose that you could go and buy a big fat book about cancer, but there's only like, you know, a couple of paragraphs about bladder cancer...I found a very good American website...called bladder café or something. (M $44 \mathrm{NB}$ )

Importance of support of family and friends. Participants valued and appreciated the support available from family and friends. For many there were new experiences to face and the need to learn new techniques (toileting, catheterization, appliance changes, etc.).

I remember that I was in the kitchen and, I stood up, you know, [suddenly] the whole floor was soaking wet [because of the leakage]. He \{partner\} was the one...cleaned me off. I just stood there, just stood there, and the tears, you know...I think he felt good about doing it for me. (F $74 \mathrm{NB}$ )

A few felt they were treated differently by family and friends after the diagnosis and surgery. They were disappointed by the withdrawal and lack of expected support.

Friends can come and go and some people exceeded your expectations, some people didn't. (M 44 NB)

Initial recovery period. Overall, hospital care after surgery was perceived to be a good experience. Participants were surprised they did not have more pain and found they were able to manage quite well. In contrast, the homecare experience was more varied. Factors such as where the person lived (i.e., how far from the hospital), the knowledge of the nursing staff in the homecare district about the surgical procedure and the care that was needed (i.e., dressings, catheterization), and the availability of family and friends to help influenced the homecare experience. Dealing with unexpected situations and the emotional reactions was distressing for some participants.

So, you know, you are a little bit uncomfortable... And lying there on the bed and realizing that my bladder is gone, you know. I was starting to feel a little bit low. But the nurses cheered me up...They were very good. (F 83 IC)

The homecare, nobody, not one person knew, had had any experiences with this. They'd had experiences with, you know, bowels, but not with bladders. (F 73 IC)

Dealing with incontinence. Urinary incontinence or leakage from a pouching system was a frustrating and challenging problem for many. Individuals attempted several strategies or different ways of dealing with the situation. However, these attempts were frequently 
on their own initiative. They had not received instruction about what to do in case of incontinence or leakage. Furthermore, health care professionals in the community setting often did not have the requisite knowledge for this post-operative challenge.

You know, you don't want to be going around wetting your pants for the rest of your life... but you don't want to die either. So you kind of go in with an open [mind]... (M $44 \mathrm{NB}$ )

I'm not happy walking around with a pad all day. I mean, I thought those days were over for me. (F $64 \mathrm{NB}$ )

I couldn't do anything [about the leaking], you know, I bought all my pants black so if I started leaking it didn't show until I got home, you know. It's been really embarrassing, and troublesome. (F 73 IC)

Adjusting to changes in body image and function. All participants experienced changes in body image and function following their surgery. These were more pronounced for participants who had an ileo-conduit, or were younger. Coping with the changes seemed linked to age, life experience, and personal comfort with one's own body prior to surgery. Most participants expressed a sense of accepting the reality of what had happened to them and the resultant changes. However, all described having to work to find ways to live with the changes and move on with their lives as best they could.

Not in a million years would I let anybody close to me with this stoma and bag and all that-and my stomach, oh, I'm disgusting. How it looks... I mean I have a bag of pee hanging on the front of me. You know, like, I find it revolting. I'm sure anybody else would! (F 73 IC)

You've got something stuck on you forever and there's no way on earth, you know, [you can leave it off]. I've been trying to find a way of how to leave it off for a day or so, but it just seems impossible. (M 79 IC)

Alterations in sexual relationships. The sense of acceptance about altered sexual function and relationships was influenced by the age of the person and their perceived "stage of life," the type of surgery and the resulting changes in the body and actual functioning, how much importance the couple placed on their physical sexual relationship, and whether there was a long-term relationship. Although there were challenges, participants described the value of intimacy between couples and how it had continued and was improved through the cancer experience.

Because I don't want to...it's [sex] very uncomfortable with this. I just have to cough and I, you know [leak]. So I wouldn't find it very appetizing to say the least. (F $64 \mathrm{NB}$ )

...if it was your husband and he loved you before... he'll still love you. I don't think a man will go out with a woman who had a, a hole in her stomach and, you know, a bag on her leg. (F 58 IC)

I've never felt inadequate in any sense, nope, not at all. I think my wife accepts that it's part of life. That sexually, that's not the most important thing...I don't think [surgery] has any impact at all ...it's improved, I think, if anything, the intimacy, you know. We can talk more freely, more openly. (M $64 \mathrm{NB}$ )

Changes in life perspectives. All participants experienced life changes because of their cancer diagnosis and resulting surgery. Many talked about feeling their lives would never be the same again and they needed to move on with their lives and find as much normality as possible. Many realized their priorities had changed and their perspectives about what was important had been altered.

You're realizing that you're not here forever. You're realizing that you're in the last quarter of your life. You realize what's important. You realize how important family is, your children are. I mean I always felt that way, but now it came to the forefront. (M $60 \mathrm{NB}$ )

\section{Focus group}

A total of six individuals (five men, one woman) attended the two follow-up focus group sessions (see Table 2). The participants indicated that the results, as described to them, reflected their experiences and had been appropriately characterized by the research team. In the subsequent discussion, the participants emphasized that additional information about bladder cancer was needed by the general public. They felt there was too little attention paid to informing the general public about the signs and symptoms of bladder cancer or the associated risk factors. For patients, there needed to be more post-operative information about what to expect. In particular, they identified wanting information about diet progression, care of scars, infections, homecare, follow-up care plans, and cancer surveillance. Participants felt there needed to be a variety of ways to distribute this information including: posters, booklets, awareness campaigns, and education packages for patients.

Finally, their advice to health care professionals centred on the need to understand more about the experiences that patients undergo. They thought more help would be available to patients if health care professionals understood more about the various surgical options and the impact on the person of the resulting body changes. In addition, participants stated that open communication with health care providers is essential, particularly the opportunity to have questions answered and to have issues and concerns explored as they relate to their specific body image and sexuality changes.

\section{Discussion and implications for practice}

This study was undertaken to describe the experiences of individuals who had undergone radical cystectomy for bladder cancer. The results provide insight into the nature of the issues that an individual experiences with this radical operation and coping with the changes in body image and function. Some of the issues are shared in common with other cancer patients while others are unique to this type of cancer and the surgical interventions. This study reflects beginning work with the special population and clearly emphasizes the need for additional research.

Essentially, this work reveals a need to provide better assistance to patients in terms of information and access to resources. There is a need to enhance and expand patient-specific educational material related to bladder cancer, reconstruction options, and surgical recovery. In addition, health care providers need information on the importance of open communication related to the patient's cancer experience; the surgical options available when a radical cystectomy is performed; and life adjustments to altered body image, function, intimacy, and sexuality.

Based on the study findings, our intent is to create a patient education tool explaining the various reconstruction options available when a radical cystectomy is performed. We hope to improve the patient's overall knowledge about the available surgical options and

\begin{tabular}{|l|l|l|}
\hline Table 2. Focus Groups & Men (N=5) & Women (N=1) \\
\hline Demographics & 4 & 0 \\
\hline Sunnybrook Patients & 1 & 1 \\
\hline University Health Network Patients & 72 & 64 \\
\hline Average Age & $60-82$ & n/a \\
\hline Age Range & 4 & 1 \\
\hline Married/Common Law & 0 & 0 \\
\hline Widow/Widower & 1 & 0 \\
\hline Divorced & 0 & 0 \\
\hline Single & 1 & 0 \\
\hline Ileal Conduit & 4 & 1 \\
\hline Neobladder & \multicolumn{2}{|l|}{} \\
\hline $\begin{array}{l}\text { Initially agreed to participate: } 13 \\
\text { Declined to participate: } 1 \text { (female with a neobladder) } \\
\text { Failed to show: 1 (male with ileal conduit) }\end{array}$ \\
\hline
\end{tabular}


facilitate patient decision-making about the best surgical approach to meet their individual needs and lifestyle. We plan to provide nursing staff education about the challenges patients face and how they can be more supportive to patients and families. We will also provide materials to facilitate teaching patients how to manage with chal- lenges such as leakage and incontinence. Finally, sharing this information and postoperative plans of care with nursing staff in the community will further enhance continuity of care for the patient as they transition from hospital to home and provide valuable information for nurses caring for this complex patient population.

\begin{tabular}{|c|c|c|}
\hline \multicolumn{3}{|l|}{ Appendix A. Interview Schedule } \\
\hline $\begin{array}{l}\text { During our time together today, I would } \\
\text { like to talk with you about several aspects } \\
\text { of your cancer experience: } \\
\text { 1. being diagnosed with cancer } \\
\text { 2. having your surgery } \\
\text { 3. what has been happening since your } \\
\text { surgery, especially the changes that have } \\
\text { occurred as a result of the cancer surgery } \\
\text { 1. To begin, I would like to hear what led } \\
\text { to your being diagnosed with cancer. } \\
\text { PROBES: What did you first notice that } \\
\text { made you think something was wrong? } \\
\text { Who diagnosed the cancer? } \\
\text { How was it diagnosed? } \\
\text { When was it diagnosed? } \\
\text { 2. What kinds of events happened in } \\
\text { terms of the surgery? }\end{array}$ & $\begin{array}{l}\text { PROBES: Who told you it was needed? } \\
\text { Did you have enough information about it? } \\
\text { Who was involved in the decision- } \\
\text { making process? } \\
\text { When did the surgery occur? } \\
\text { What was it like for you in the hospital? } \\
\text { What was done during the surgery? } \\
\text { What was it like for you at home just } \\
\text { after the surgery? } \\
\text { 3. What kinds of changes have you noticed } \\
\text { since then that you think resulted from } \\
\text { the surgery? } \\
\text { PROBES: What is different now than } \\
\text { before the surgery? } \\
\text { What are you able to do and not able to } \\
\text { do as a result of the surgery? } \\
\text { How do you feel about the changes? }\end{array}$ & $\begin{array}{l}\text { What impact have the changes: } \\
\text { had on you? } \\
\text { on your feelings about yourself? } \\
\text { on your feelings about your body? } \\
\text { on your sense of who you are? } \\
\text { on your sense of being a woman/man? } \\
\text { 4. Because of the type of surgery you have } \\
\text { had, there can be changes in sexual } \\
\text { intimacy and/or relationships. What has } \\
\text { your experience been since your surgery } \\
\text { in this area? } \\
\text { 5. Is there anything else you would like to } \\
\text { tell me about your experiences with cancer } \\
\text { and living since the diagnosis and surgery } \\
\text { that we have not already talked about? } \\
\text { Thank you for your participation }\end{array}$ \\
\hline
\end{tabular}

\section{References}

Beitz, J.M., \& Zuzelo, P.R. (2003). The lived experience of having a neobladder. Western Journal of Nursing Research, 25(3), 294-316.

Canadian Cancer Society/National Cancer Institute of Canada. (2009). Canadian Cancer Statistics 2009. Toronto, ON: Author.

Connelly, L.M., \& Yoder, L.H. (2000). Improving qualitative proposals: Common problem areas. Clinical Nurse Specialist, 1(2), 69-74.

Dutta, S.C., Chang, S.C., Coffey, C.S., Smith, J.A. Jr., Jack, G., \& Cookson, M.S. (2002). Health related quality of life assessment after radical cystectomy: Comparison of ileal conduit with continent orthotopic neobladder. Journal of Urology, 168(1), 164-167.

Gerharz, E.W., Mansson, A., Hunt, S., Skinner, E.C., \& Mansson, W. (2005). Quality of life after cystectomy and urinary diversion: An evidence-based analysis. Journal of Urology, 174(5), 1729-1736.

Giorgi, A. (1985). Sketch of a phenomenological method. In A. Giorgi (Ed.), Phenomenology and Psychological Research (pp. 8-22). Pittsburgh, PA: Pittsburgh Duquesne University Press.

Hart, S., Skinner, E.C., Meyerowitz, B.E., Boyde, S., Lieskovsky, G., \& Skinner, D.G. (1999). Quality of life after radical cystectomy for bladder cancer in patients with an ileal conduit, cutaneous or urethral Kock pouch. Journal of Urology, 162(1), 77-81.

Henningsohn, L., Steven, K., Kallestrup, E.B., \& Steineck, G. (2002). Distressful symptoms and well-being after radical cystectomy and orthotopic bladder substitution compared with a matched control population. Journal of Urology, 168(1), 168-174.

Kulaksizoglu, H., Toktas, G., Kulaksizoglu, I.B., Aglamis, E., \& Unlüer, E. (2002). When should quality of life be measured after radical cystectomy? European Urology, 42(4), 350-355.

Lagana, L., Classen, C., Caldwell, R., McGarvey, E.L., Baum, L.D., Cheasty, E., et al. (2005). Sexual difficulties of patients with gynecological cancers. Professional Psychology: Research \& Practice, 36(4), 391-399.

Lincoln, Y.S., \& Guba, E. (1985). Naturalistic Inquiry. Thousand Oaks, CA: Sage Publications Inc.

Madeb, R., \& Messing, E.M. (2004). Gender, racial and age differences in bladder cancer incidence and mortality. Urologic Oncology, 22(2), 86-92.

McGuire, M.S., Grimaldi, G., Grotas, J., \& Russo, P. (2000). The type of urinary diversion after radical cystectomy significantly impacts on the patient's quality of life [see comment]. Annals of Surgical Oncology, 7(1), 4-8.

Nordström, G.M., \& Nyman, C.R. (1992). Male and female sexual function and activity following ileal conduit urinary diversion. British Journal of Urology, 70(1), 33-39.

Patel, A.R., \& Campbell, S.C. (2009). Current trends in the management of bladder cancer. Journal of Wound, Ostomy and Continence Nursing, 36(4), 413-421.

Porter, M.P., \& Penson, D.F. (2005). Health-related quality of life after radical cystectomy and urinary diversion for bladder cancer: A systematic review and critical analysis of the literature. Journal of Urology, 173, 1318-1322.

Sandelowski, M. (1986). The problem of rigor in qualitative research. Advances in Nursing Science, 8(3), 27-37.

Sandelowski, M. (1993). Rigor or rigor mortis: The problem of rigor in qualitative research revisited. Advances in Nursing Science, 16(2), 1-8.

Sandelowski, M. (1995). Sample size in qualitative research. Research in Nursing \& Health, 18(2) 179-183.

Sandelowski, M. (1997). "To be of use": Enhancing the utility of qualitative research. Nursing Outlook, 45(3), 125-132.

Schover, L.R. (2004). Sexuality after treatment of pelvic cancer (pp. 186-195). Linthicum, MD: American Urological Association.

Somani, B.K, Gimlin, D., Fayers, P., \& N'dow, J. (2009). Quality of life and body image for bladder cancer patients undergoing radical cystectomy and urinary diversion-A prospective cohort study with a systematic review of literature. Urology, 74(5), 1138-43.

Tabano, M., Condosta, D., \& Coons, M. (2002). Symptoms affecting the quality of life in women with gynecologic cancer. Seminars in Oncology Nursing, 18(3), 223-230.

Thorne, S., Kirkham, S.R., \& MacDonald-Emes, J. (1997). Interpretive description: A noncategorical qualitative alternative for developing nursing knowledge. Research in Nursing \& Health, 20(2), 169-177.

Zippe, C.D., Raina, R., Shah, A.D., Massavayi, E.Z., Agarwal, A., Ulchaker, J., et al. (2004). Female sexual dysfunction after radical cystectomy: A new outcome measure. Urology, 63(6), 1153-1157. 